\title{
Interprofessional working: adoption assessments for people living with HIV
}

\begin{tabular}{|r|l|}
\hline Journal: & International Journal of Human Rights in Healthcare \\
\hline Manuscript ID & IJHRH-02-2017-0005.R2 \\
\hline Manuscript Type: & Research Paper \\
\hline Keywords: & $\begin{array}{l}\text { HIV, adoption, interprofessional working, interpretative phenominological } \\
\text { analysis }\end{array}$ \\
\hline \multicolumn{2}{|l}{} \\
\hline
\end{tabular}




\section{Introduction}

In 2013, approximately 107,800 people were living with HIV infection in the UK. Of these, 3,710 had CD4 count levels above 500 cells/mm3; they adhered to antiretroviral treatment and were living steadily (Public Health England, 2014). Those with suppressed viral loads may not require treatment and may live normal lives. The prevalence of HIV falls within the reproductive age range of $15-59$ years. It is likely that men and women in this group will consider parenthood, be it naturally or through surrogacy or adoption (Gerrand, 2012). More recent work by Townsend et al. (2014) has found the risks of mother-to-child transmission in the UK to be significantly lowered to 0.46 . Their study reports the continued desire to be biological parents within this group. Nevertheless, in some cases, child adoption becomes a preferred choice, often after other options have been explored (Paiva et al., 2003). Official UK adoption statistics do not publish information about the numbers of potential adopters who are HIV+ and there no existing studies that help to quantify the issue. Therefore, it is difficult to assess the number of potential adopters who are HIV positive. Nonetheless, adoption is one of the options for HIV positive individuals who wish to be parents.

Opportunities for early treatment have reduced HIV-related illnesses, the progression to AIDS or AIDS- and non-AIDS-related chronic illnesses, and have increased life expectancy (Sherr et al., 2010). This approach requires consistent and sustained delivery of health, treatment and social care interventions in line with clinical treatment guidelines (British HIV Association, 2013). Public Health England and other organisations such as the British HIV Association (BHIVA) and Social Care Institution for Excellence (SCIE) rely on clinical, community and outreach services in monitoring and improving long-term successful outcomes for PLWHIV (people living with HIV) (BHIVA, 2013; Public Health England, 2014). Alongside these, adoption protocols and action plans encourage adoption pathways that use efficient collaborative models for information-sharing and accurate recording to ensure that 
the needs of prospective adoptive children and adopters are accurately represented (Selwyn et al., 2008; Department for Education, 2012a).

While interprofessional partnerships are seen as the preferred method of working in adoption (Selwyn et al. 2008), there is little evidence to show the effectiveness of collaborative working for PLWHIV. Selwyn et al. (2008) found improvements in adoption interagency working practices; the study also found assessment documents, relied upon for informationsharing such as core assessment, the Adoption Medical, and Child Permanency Report, are often poorly written with poor articulation and missing information. This creates barriers, tensions and power struggles in decision-making (Atkinson et al., 2005). This is important in the PLWHIV adoption process because the literature around adoption and HIV identifies a 'stack of stigmas' associated with HIV-related infertility, HIV itself and adoption (Goldberg et al., 2011; Gibson and Fair, 2015).

Fear of HIV testing within adoption processes has led to PLWHIV withdrawing their intent. While confidentiality and stigma issues pose concerns for effective collaboration, the need to share information sensitively remains central, offering best outcomes for PLWHIV and adoptive children arising from shared language and meaning (Atkinson et al., 2005). Newmeyer et al. (2011) provided a snapshot of potential barriers in a study of 14 Canadian sero-discordant couples, finding in some cases HIV couples were prevented from accessing both fertility treatment and adoption processes. Other couples perceived resistance from adoption agencies who denied equal access to adoption because they were HIV positive. There were also reports that adoption opportunities were confined to disabled or HIVpositive children. Newmeyer et al. (2011) concluded that PLWHIV adoption-related medical examinations would lead to stigma and disqualification from the adoption process. On the other hand, however, it is important to understand how HIV intersects with other layers of stigma that compromise social justice (see Diagram 1). Logie et al. (2011), identify that the intersection between HIV and various stigmas such as gender, sexuality, sexual orientation, 
As good interprofessional working is well documented in areas such as occupational therapy, mentorship and rehabilitation programmes that foster lifestyle changes, stability, cognitive support and home management (Tunnicliff et al., 2013), it makes sense to examine the potential for a similar approach in HIV-related adoption. Research indicates this may increase efficiency within health and social care systems, allowing holistic provision of services for those with a broad spectrum of needs, coordinated by different service providers/professionals (Atkinson et al., 2005; McColl and Dickenson, 2009). Forward planning of health services for PLWHIV can facilitate the management of sensitive issues disclosed during adoption processes, as well as consider the long-term management of the condition (Tran et al., 2010). This planning also allows consideration of HIV strategies for both child and potential adoptive parent. To work this requires interprofessional partnership. Generally, partnership working in adoption is improving (Selwyn et al., 2009).

Moreover the British Association for Sexual Health (BASH), National Institute for Health and Care Excellence (NICE) and other healthcare institutions are interested in ensuring that interprofessional working is at the heart of preventative care and its delivery for PLWHIV (BHIVA, 2013). Despite this, there is some evidence of barriers, particularly with the sharing 
of sensitive information. For example, Underhill et al. (2016) found sharing specific health information can create room for stigma and discrimination. The study advocated for health records of prospective adoption parents to remain confidential from those without expert knowledge or formal qualifications in managing regulations around specific health conditions such as HIV. Further, Underhill et al. (2016) argue that, PLWHIV should be warned and counselled about disclosure and potential discrimination.

Cameron et al.'s (2012) description of "discrete joint working models" offers a potential model for the adoption process. In this model, collaboration between professionals takes place with agencies that operate independently. Partnership working takes a "targeted approach", focusing on sharing information between professionals working with PLWHIV to inform assessments and provide guidance on how adoption services and adoption plans should be delivered and managed. Studies looking at joint-working generally report serviceuser satisfaction, better social well-being and improvements in the quality of life and lifestyles of service users at the centre of joint working initiatives (Cameron et al., 2012). However, existing studies looking at HIV and child adoption suggest that many PLWHIV going through the adoption process experience substantial dissatisfaction due to the stigma and discrimination around HIV that prevents their applications from being considered within adoption systems (Gerrand, 2012).

Drawing on an Interpretative Phenomenological Analysis (IPA) study, looking at the lived experiences of PLWHIV going through fertility treatment and the adoption process, this paper will present themes around interprofessional working in respect of HIV-related adoption. The views and perceptions of five participants (both couples and single potential adopters) who went through various stages of the adoption process will be analysed. The paper argues that professionals from all agencies involved in the health and social care of PLWHIV, including charitable organisations, should be embedded within models of interprofessional working within adoption. Collaborating with all relevant professionals will 
provide a range of perspectives, inclusive adoption strategies for PLWHIV and holistic considerations of applications made by PLWHIV (Atkinson et al., 2005). This approach aims to address the theme of HIV as a long-term condition in those seeking to adopt and any gaps in HIV knowledge which may enhance the understanding of normalcy principles for PLWHIV who are stable in their health and lifestyles.

Empirically, however, it is unclear what interprofessional models are in place for PLWHIV who are applying to become adoptive parents, and whether these are consistent and integrated within adoption teams. In advocating such services there is a need for interprofessional working that is distanced from tokenistic non-HIV-related practices. As there is scant literature on interprofessional working strategies for PLWHIV seeking to adopt, the rationale for this paper lies in the need to understand and explore the value of interprofessional working between professionals. It also explores the impact of this model on PLWHIV going through the adoption process.

\section{***insert diagram 1 about here ${ }^{* * *}$}

\section{Methodology}

\section{Participant Recruitment}

The study received ethical approval from the University of Surrey Ethics Committee and was supported by the Terrance Higgins Trust (THT). Recruitment was led by HIV charitable organisations who promoted this study. In addition, other charitable organisations and adoption agencies also promoted the study. The research was advertised through the THT my HIV confidential web forum, leaflets, adoption agencies and through HIV-related radio shows. THT awarded the lead researcher with honorary researcher status, giving an official connection to the organisation. Eligible participants contacted the researcher directly through a nominated telephone number and were given full information about the study. Study information was also shared through a preliminary screening telephone call. Written consent was given by participants prior to the interview commencing. Participants were interviewed either at THT or at the venue of their choice. Incentives were offered to cover expenses. At 
every point, potential participants were offered an option to opt out. All potential participants who contacted the researcher agreed to take part in the study.

\section{Characteristics of Participants}

This study is part of a larger study which explored the lived experiences of PLWHIV who had undertaken either fertility treatment and/or adoption. The main study recruited eleven respondents (seven individuals and four couples). See Table 1 for the ethnic description of the larger sample. Three of the individual prospective adopters in the original sample were from a white background, a further three were black and one was Asian. Of the couples, three were white and one was black.

\section{${ }^{* * *}$ Insert Table 1 about here ${ }^{* * *}$}

As the purpose of the study described in this paper was to explore the UK adoption experiences of PLWHIV, it focused only on those who were currently engaged in the adoption process at the time of the study. One of the original participants was in the process of international adoption and therefore excluded from this study. A further five of the original participants were exploring or had accessed fertility treatment and were thus excluded from this study. The study thus examines five in-depth, semi-structured interviews involving two single interviewees and three couples who had accessed adoption services while receiving support through HIV-related charitable organisations in England, but were not accessing fertility treatment at the time of the study.

Table 2 describes all of the participants in the original study. The final column in the table indicates whether they were included in this study or not. The sample for this study included two single homosexual men and three heterosexual couples. All of the participants were white. It is unclear whether or not this suggests that formal adoption is not common among Black and Ethnic Minorities although earlier studies identify that culturally and gender- 
specific expectations may force PLWHIV to have children biologically (Newmeyer et al., 2011).

\section{${ }^{* * *}$ Insert Table 2 about here ${ }^{* * *}$}

This study's participants' experiences range from the adoption consultation stage to the assessment stage and post-adoption. Participants in the early stages of adoption applications were involved with child adoption services for a period of at least three months. This ensured that participants' experiences were considerable. Successful adopters were either waiting to have their children placed in their care or already had their children living with them. Therefore, individual narratives will reflect varied experiences within the adoption system. Their experiences are interpreted and understood within their contexts, although common experiences are underlined from an interpretative engagement with the data.

\section{Data Collection}

Semi-structured in-depth interviews lasted 60 to 120 minutes. Interpretative Phenomenological Analysis (IPA) methodologies were used to draw on experiences and to make meaning (Smith, 2004). Participants were interviewed as individuals or couples. All interviews were conducted by the researcher and were recorded and transcribed verbatim. An interview guide was used to conduct the interviews.

\section{Data Analysis}

The researcher used the IPA framework for analysis (Smith, 2004) to understand and make sense of the participants' narratives. Initially, recorded interviews were transcribed and inputted into NVivo software for qualitative data analysis. Data coding and cluttering of themes was achieved through cross-case analysis. A staged and cyclical IPA procedure for analysis was used to provide a robust analysis. Due to the sensitive nature of HIV and adoption, the researcher offered sensitivity to the context of experiences when engaging with, and becoming submerged in, the analysis. 
Rigorous attention was given to the data through case-by-case and cross-case analysis allowing the researcher to become immersed in the data during analysis. Through embracing inter-categorical intersectionality approaches (McCall, 2005), the analysis looked at how participants made sense of how HIV-related stigma and discrimination were not always in isolation from other contextual factors such as race, gender and sexual orientation. Participants interpreted their experiences at the individual level (e.g. being male or female, their sexual orientation, or social class) and they interlocked them with what they considered to be discriminatory or oppressive practices they observed at the macro level of society) to make sense of what they perceived as social injustices that prevented them from successfully accessing adoption.

The accuracy and validity of data was checked with participants during data collection to avoid participants revisiting distressing narratives after their interview. Direct quotations were used to ensure illustrative accuracy. The lead researcher met with two other researchers for briefing, to discuss and refine the analysis. This ensured the construction of meaning through understanding participants' perceptions, feelings and experiences endured during the adoption process. A thematic analysis of recurring themes was followed within the stages of IPA to provide structure to the concepts and issues raised by participants.

\section{Limitations of the Study}

This study consists of only five interviews. The advantage of a small sample size is that it enabled the researcher to explore deeper into individuals' personal experiences and perceptions using an interpretative approach (Smith and Osborne, 2007; Flowers et al., 2011). This is in line with IPA analysis (Smith, 2008). It is also not unusual in a hard-toreach population to have smaller sample sizes (van Eeden-Moorefield et al., 2008). 
The sample for this study consisted of only couples and individuals from a white background despite the original sample including a more diverse group of individual and couple prospective adopters. This may be because the original sample included both those seeking, or those already engaged in, fertility treatment and adoption. As mentioned above, there can be cultural reasons why certain groups prefer not to adopt (Gerrand, 2012). In this case, this may mean that the results of this study are not generalizable to a wider population. Nonetheless the study does produce findings that are of value to the debate and the future development of services.

\section{Results}

This part of the paper will focus on the main aspects of interprofessional working that emerged from the IPA analysis. The extracts were chosen from many themes that emerged in the analysis of the main study because they relate most closely to the concept of interprofessional working. The extracts from the interviews depict issues such as sensitivity in information-gathering, communication between participant/s and professionals, and the potential reluctance of professionals to accept expert advice. These extracts portray features that form part of the day-to-day operation of a social worker. In the case of PLWHIV, where the issues being dealt with are complex in terms of people's health but also in terms of the social and cultural context, interprofessional working becomes an even more important framework to explore.

\section{Recording and sharing factual information: "I did not want to be misrepresented"}

Social workers cannot be experts in all areas of their practice. When working with service users presenting uncommon health issues such as HIV, how issues are approached is very important. In the case of Alan who was a single, white homosexual adopter, how information was collated and recorded had potential long term-repercussions: 
I did not want to be misrepresented. At the end of the day my child may read my file when he is older, other professionals will read it and make judgements about me. I just didn't want that. Well, she (the social worker) was brilliant. [Alan, single adopter, white, homosexual]

The importance of accurate representation was echoed by another couple Hillary and Marius who went through the adoption process as a serodiscordant heterosexual couple. For Alan, his anxieties were reduced because he viewed the social worker's capabilities positively. There is a real sense of worry that misrepresentation will have an impact on the adoptive child and how others may interpret that information. In that same vein, some participants felt that preparing for adoption panels in order to answer a diverse range of questions would provide an opportunity to demonstrate their capability of adopting.

For example, Hillary and Marius' experience depicts how they prepared for an adoption panel and how they were ready to respond to questions that related to dual diagnosis. Although Hillary was HIV negative, Marius was HIV positive with haemophilia. The couple were worried that this dual diagnosis was likely to affect their chances to adopt. The fact that the social worker's report contained sufficient relevant health information appears to have made such a line of inquiry unnecessary.

We went to the panel quite geared up to be asked about mixed illnesses. We were surprised that the panel did not have to go through HIV all over again. The panel got factual information they needed from the social worker's report in terms of, what is your prognosis, what is your CD4 count. That's all they were interested in. Thinking about it, they did not ask us about what we will do if you (Marius) had got ill. I was expecting them to ask. Maybe they were worried about being accused of stigma and discrimination. That would have been a fair question to me. [Hillary and Marius, a couple affected by HIV and haemophilia, attending an adoption panel]

Hillary and Marius recognised the relevance of questions pertaining to contingency planning in the event of illness. In this instance, exploratory interview questions in an adoption panel were seen as reasonable by the potential adopters opposed to stigmatising. In this case factual reporting supported the concept of discrete joint working and collaboration where sharing sensitive information increased the panel's knowledge and at the same time reduced 
the need to revisit HIV, thus showing the importance of the social workers' communication and reporting skills.

\section{Openness to information sharing: "Call them, be my guest"}

Generally, all participants were open to the idea of practitioners collaborating with other professionals in order to gather information that informs their assessment. For instance, Gary was a single homosexual man who had experienced poor mental health after contracting HIV and was open to social workers contacting mental health services for further information:

The first social worker had not assessed someone with HIV before. She wanted more information about my mental health and my HIV. I said call them, be my guest. Within a week they had rung and said yes, we want to assess you. [Gary, white, homosexual male]

This suggests that information-sharing can yield positive results for PLWHIV. This excerpt also portrays willingness by potential adopters to cooperate with an assessment process that requires collaborating with other professionals.

Professional reluctance to accept expert advice: "You might not live long enough to have a child"

When it comes to decision-making and consideration of medical advice, two couples in this study indicated that some social workers and adoption panels were reluctant to accept the advice they were given by HIV consultants. For example, Gabriella and Brad report their observation:

Social services refused to accept expert advice from my HIV treating consultant. The consultant wrote a letter about my HIV status and lifestyle but the social worker did not put these through. [Gabriella and Brad, HIV+ heterosexual couple (both +)]

Another example relates to Alan's case, it appears that a decision was made without the necessary consultation with relevant health professionals. Alan reported that this distressed him: 
The social worker wrote, you might not live long enough to have a child. I said, how can you say that? You have not contacted my HIV consultant or my GP. I was absolutely angry. [Alan, single adopter, white, homosexual]

Alan demonstrates the importance of social workers communicating with HIV consultants and other professionals to avoid making negative judgements that are not supported by expert opinion. All participants presented in this paper support the need for professionals to use sensitive language. It is important to consider using sensitive language rather than communicating to a service user that they will not live long enough, especially without medical evidence.

Alan relayed how his experience led him to query decision-making by adoption panels after they analysed health information provided by medical specialists. He demonstrated a sense of ambiguity around why his application was rejected. Others with similar experiences demonstrated feelings of upset, powerlessness and unfair treatment.

Social Services rang me up and they said based on their medical advisor, we are not clear on what your life prognosis is and therefore we are finding it very difficult to decide whether we should go forward or not. I could not accept that the medical advisor for the panel could not make the decision one way or the other. What I was told was that they sat on the fence. They would not advise one way or the other. I think this is generally true for doctors but maybe l'm wrong. They are very risk averse. They will not put anything in black and white unless they are sure they can back it up. [Alan, single adopter, white, homosexual]

This could be seen as indirect discrimination associated with fear of making wrong decisions. This concern was expressed across the board. On the other hand, opportunities for collaboration are noted by Marius (HIV+male who subsequently successfully adopted two children) but he felt these were not fully utilised because he felt the professionals were overcautiousness:

They refused to accept my application based on HIV. They were just over-cautious. That is the problem and this leads to many people feeling prejudiced against, especially when they are not clear of ins and outs of HIV. They could have sought clarification from my haemophilia consultant and my HIV consultant; I gave them all the information. [Marius, HIV+ male]

The above account indicates the importance of exploring and seeking further information in order to gain a rounded understanding of the prospective adopters' circumstances. Without 
this, it appears that PLWHIV may feel and indeed be marginalised and prejudiced against, in that, lack of clarity increases concerns by PLWHIV that their chances to adopt are prevented by HIV itself, as suggested:

They did not give us the reason for refusing. They said, this has nothing to do with HIV (laugh!). Obviously, it is. It is a concern that adoption consultancy does not share a common ground; there is still a disparity from health professionals on what is a healthy person [versus] an unhealthy person. You are relying on a consultant who is going to support you. Our consultant knew the facts not the adoption consultant. [Hillary HIV-female adopting with her HIV+ partner]

Hillary is clearly dissatisfied about the misunderstanding and disparities between health professionals and adoption social workers regarding what constitutes a healthy person living with HIV. Reductionism in the sense of over-simplifying the complexities between HIV and its impact on adoption appears connected with how decisions were separated from HIV even though HIV was connected or embodied to the PLWHIV seeking to adopt. Hillary's excerpt suggests that PLWHIV may rely on medical expertise possessed by HIV consultants who obtain medical facts that will be useful to other professionals, as they may contribute towards decision-making.

\section{Discussion}

The findings in this paper demonstrate a lack of collaboration between those assessing PLWHIV through the adoption system with HIV experts. This has been reported in other studies (Hekkink et al., 2005 and Wilson et al., 2005) that suggest HIV expertise and quality of care are better provided by HIV experts than non-HIV clinical experts. Thus, there needs to be transparent processes around how HIV-related expert contributions are welcomed by social workers, including useful contributions by HIV charitable organisations. On the other hand, collaboration should be seen as a routine part of assessment to include experts rather than as an option. Specifically, those with expert knowledge about HIV, such as HIV consultants and HIV counsellors, must be consulted fully prior to any adoption decisions being made. 
Findings corroborate with Paiva et al. (2003) and Schofield and Ward (2011) highlighting that reluctance in joint working results in feelings of powerlessness. Unsupportive systems, HIV discrimination and stigma raise the potential that PLWHIV will be refused opportunities for adoptive parenthood (Newmeyer et al., 2011). It still remains uncertain about the extent to which PLWHIV are fairly considered within the system, given the small sample in this study. Nevertheless, it is clear from participants in this study that good communication and accurate representation of PLWHIV going through adoption is important. It is vital that social workers do not lose sight of the long-term consequences that misrepresentation may have on adoptive parents and their adopted children.

Thus, this paper adds to the evidence base that supports the UK policy of cross-agency partnerships to facilitate best practice (BHIVA, 2013). Working in isolation can leave any potential adopter feeling that the adoption process is unfair. However, efforts to improve joint working for PLWHIV are evident in healthcare settings (Tunnicliff et al., 2013). It is recognised that confidentiality around HIV positive adopters can make collaboration challenging, given the sensitive nature of HIV, secrecy and stigma attached to the illness. One way to manage this would be to apply social work values and ethical practices and to use social work approaches such as cultural competence, HIV-culturally-sensitive language (that is non-offensive or non-derogatory), and relationship-based and strength-based models. Being HIV inclusive in adoption social work would require drawing on the expertise of those in the HIV voluntary sectors who are the main providers of support to PLWHIV. Also, existing adoption procedures should include an additional section to elaborate the need for joint working for PLWHIV potential adopters. This could include structures that further facilitate censored and consensual information sharing within existing protocols. From this, PLWHIV may be reassured about the transparency and consistency of decisionmaking. Integrated adoption practices can increase knowledge and expertise through joint learning and understanding of what it means to live healthily with HIV. This will help to 
reduce disparities around 'HIV today' and will lessen the repetition of preconceived judgements linked to HIV.

\section{Conclusion}

This paper identified gaps perceived by PLWHIV around interprofessional working in adoption. There is a need to develop additional guidance about interprofessional working for PLWHIV to develop social workers' core skills that call for collaborative working between professionals, HIV experts and their contributions to the adoption process.

The study suggests that without improved communication and interprofessional working between adoption social workers and HIV consultants, it may lessen the chances of PLWHIV being considered positively within the adoption. Hence, interprofessional working should include coordinating with not just HIV consultants or support workers in HIV voluntary sectors but also with other professionals, thus representing a holistic picture of those PLWHIV when going through the adoption process. To conclude, HIV stigma and discrimination cannot be seen in isolation. It is important for social workers to understand PLWHIV as unique individuals by recognizing the importance of intersectionality and structural and individual-level influences that create barriers for PLWHIV coming through the adoption system. Decisions about whether PLWHIV are suitable to adopt should be based on good partnership working and whether or not PLWHIV will be suitable to offer good parenthood (see Diagram 1 for a visual framework explaining this depiction). Ultimately, integrative partnership approaches to supporting PLWHIV seeking to adopt will bring the health and social care worlds together to become more holistic, as opposed to taking a reductionist approach.

\section{Cautionary note:}

Establishing the views of social workers is a recommendation for future research. This paper opens a dialogue for discussing issues around the adoption for PLWHIV and informing 
professionals about increasing opportunities for PLWHIV to adopt children where there is a high demand for adoptive parents. The views of participants in this study need to be placed within the body of knowledge.

\section{Acknowledgements}

I am grateful to all participants living with HIV who took part in this study, the Terrence Higgins Trust, and African Eye for helping to promote this study. I thank all the agencies and charitable organisations supporting PLWHIV who helped promote this study.

\section{Declaration of interest}

There are no conflicts of interest. This paper is drawn from a doctoral thesis and some concepts may be linked to other papers to be published in due course. The doctoral thesis was subject to peer review by way of a supervisory support and internal and external examinations. The author alone is responsible for this particular paper. 


\section{References}

Atkinson, M., Jones, M. and Lamont, E. (2005), Multi-agency Working and its Implications for Practice: A Review of the Literature. CfBT, Reading.

British HIV Association (2013), "Standards of care for people living with HIV in London", available at: http://www.bhiva.org/standards-of-care-2013.aspx/.

Cameron, A., Lart, R., Bostock, L. and Coomber, C. (2015), "Factors that promote and hinder joint and integrated working between health and social care services", Social Care Institute for Excellence. Available at: http://www.crisiscareconcordat.org.uk/wpcontent/uploads/2014/04/briefing41.pdf (accessed 20 March 2016).

Cooper, D., Moodley, J., Zweigenthal, V., Bekker, L., Shah, I. and Myer, L. (2009), "Fertility intentions and reproductive health care needs of people living with HIV in Cape Town, South Africa: Implications for integrating reproductive health and HIV care services", AIDS Behaviour, Suppl. 1, pp. 38-46.

Department for Education (2013), Working Together to Safeguard Children: A Guide to Interagency Working to Safeguard and Promote the Welfare of Children. DfE, London.

Department for Education (2012a), An Action Plan for Adoption: Tackling Delay. DfE, London.

Department for Education (2012b), Supporting Families Who Adopt. DfE, London.

Department of Health (DH) (2010), Equity and Excellence: Liberating the NHS. DfE, London.

Gerrand, P.A. (2012), "Developing a culturally relevant adoption model in South Africa: the Way Forward", International Social Work. Vol. 38 No. 1, pp, 1-11.

Gibson, E. and Fair, D.C. (2015), “I would do HIV adoption 100 times over again': an exploratory study on families with internationally adopted children with PHIV", Adoption Quarterly, Vol. 19 No.1, pp. 26-43. 
Goldberg, A.E., Kinkler, L.A. and Hines, D.A. (2011), "Perception and internalization of adoption stigma among gay, lesbian, and heterosexual adoptive parents", Journal of GLBT Family Studies, 7 No. 2, pp. 132-54.

Hekkink, C.F., Wigersma, L., Yzermans, C.J. and Bindels, P.J.E. (2005), "HIV nursing consultants: Patients' preferences and experiences about the quality of care", Journal of Clinical Nursing, 14 No. 3, pp. 327-33.

Lind, J., and Lindgren, C. (2017), "Displays of parent suitability in adoption assessment reports", Child and Family Social Work, 22 Suppl. 1, pp. 53-63. doi:10.1111/cfs.12305.

Logie, C.H., James, L., Tharao, W. and Loutfy M.R. HIV, gender, race, sexual orientation, and sex work: a qualitative study of intersectional stigma experienced by HIV-positive women in Ontario Canada. PLOS Medicine, Vol. 8 No. 11. doi:10.1371/journal.pmed.1001124.

McColl, M.A. and Dickenson, J. (2009), Inter-Professional Primary Health Care: Assembling the Pieces. A Framework to Build your Practice in Primary Health Care. CAOT Publications ACE, Ottawa.

Newmeyer, T., Tecimer, S.N., Jaworsky, D., Chihrin, S., Gough K., Rachils, A., Martin, J., Mohammed, S. and Loutfy, M.R. (2011), "Case series of fertility treatment in HIV discordant couples (male positive, female negative): The Ontario experience. PLoS One, Vol. 6 No.1, pp. 1-8.

Paiva, V., Ventura-Filipe, E., Santos, N., Novaes, Lima , T.N., and Segurado, A.C. (2003), Desire to have children: Gender and reproductive rights of men and women living with HIV: A challenge to health care in Brazil. AIDS Patient Care and STDs, Vol. 21 No. 4, pp. 268-77.

Public Health England (2014), HIV in the United Kingdom 2014 Report. Available at: https://www.gov.uk/government/uploads/system/uploads/attachment data/file/40166 2/2014 PHE HIV annual report draft Final 07-01-2015.pdf (accessed 25 January 2016).

Selwyn, J., Sempik, J., Thurston, P. and Dinithi, W. (2009), Adoption and the inter-agency fee. Hadley Centre for Adoption and Foster Care Studies, School of Policy Studies, 
University of Bristol and Centre for Child and Family Research, Loughborough University. Department for Children, Schools and Families.

Selwyn, J., Harris, P., Nawaz, S., Wijedasa, D. and Wood, M. (2008), Pathways to permanency for Black, Asian and Mixed Ethnicity children: dilemmas, decision making and outcomes. Retrieved http://www.adoptionresearchinitiative.org.uk/briefs/DCSF-RBX-13-08.pdf (accessed 13 May 2016).

Schofield, G., and Ward, E. (2011), Understanding and Working with Parents of Children in Long-term Foster Care. Jessica Kingsley, London.

Sherr, L., Lampea, F.C., Clucasa, C., Johnson, M., Fisher, M., Date H.L., Anderson, J., Edwards, S., Smitha, C.J., Hill, T., and Harding, R. (2010), Self-reported nonadherence to ART and virological outcome in a multiclinic UK study. AIDS Care, Vol. 22 No. 8, pp. 939-45.

Smith, J.A. (2004), Reflecting on the development of interpretative phenomenological analysis and its contribution to qualitative research in psychology. Qualitative Research in Psychology, Vol 1 No. 1, pp. 39-54.

Tran, N.T., Hallerdin, J.M., Flowers-Maple, C. and Moskosky, S.B. (2010), Collaboration for integration of HIV prevention at Title X Family Planning Service delivery sites. Public Health Report, 125 Suppl. 1, pp. 47-54.

Townsend, C.L., Byrne, L., Cortina-Borja, M., Thorne, C., de Ruiter, A. and Lyall H, et al. (2014), Earlier initiation of ART and further decline in mother-to-child HIV transmission rates, 2000-2011. AIDS. 28, pp. 1049-57.

Tu, D., Belda, P., Littlejohn, D., Pederson, J.S., Valle-Rivera, J. and Tyndall, M. (2013), Adoption of the chronic care model to improve HIV care in a marginalized, largely aboriginal population. Canadian Family Physician, Vol 59 No. 6, pp. 650-7.

Tunnicliff, S.A., Piercy, H., Bowan, C.A., Hughes, C.D. and Goyder E.C. (2013), The contribution of the HIV specialist nurse to HIV care: A scoping review. Journal of Clinical Nursing, 22, pp. 23-4. doi:3349-3360. 
Underhill, A.A., Kennedy, V.L., Lewis, J., Ross, L.E., and Loutfy, M. (2016). Assessing access for prospective adoptive parents living with HIV: an environmental scan of Ontario's adoption agencies. AIDS Care: Psychological and Socio-medical Aspects of $A I D S / H I$, Vol, 28 No. 10, pp. 1269-1273.

van Eeden-Moorefield, B., Proulx, C.M., Pasley, K. (2008) A comparison of internet and face-to-face (FTF) qualitative methods in studying the relationships of gay men. Journal of GLBT Family Studies, Vol. 4 No. 2, pp. 181-204. doi: 10.1080/15504280802096856.

Wilson, I.B., Landon, B.E., Hirschhorn, L.R., Mclnnes, K., Ding, L., Marsden, P.V. and Cleary, P.D. (2005), Quality of HIV care provided by nurse practitioners, physician assistants and physicians. Annals of Internal Medicine, Vol 143 No.10, pp. 729-73. 
Table 1: Ethnic profile of original study sample

\begin{tabular}{|l|l|l|l|l|}
\hline Ethnicity & White & Black & Asian & Total \\
\hline & & 3 & 1 & \\
\hline $\begin{array}{l}\text { Individual } \\
\text { Prospective } \\
\text { Adopters }\end{array}$ & $\mathbf{3}$ & 3 & 1 & 7 \\
\hline $\begin{array}{l}\text { Couple } \\
\text { Prospective } \\
\text { Adopters }\end{array}$ & $\mathbf{3}$ & 1 & 0 & 4 \\
\hline
\end{tabular}

Table 2: Summary of participants and outcome of parenting option sought

\begin{tabular}{|c|c|c|c|c|c|}
\hline Participant & Pseudonyms & Demographic & Option & Outcome & Included \\
\hline Interviewee 1 & Gary (White) & $\begin{array}{l}\text { Single } \\
\text { homosexual } \\
\text { man }\end{array}$ & $\begin{array}{l}\text { Adoption } \\
\text { only }\end{array}$ & Unsuccessful & Included \\
\hline Interviewee 2 & $\begin{array}{l}\text { Hillary (White) } \\
\text { Marius (White) }\end{array}$ & $\begin{array}{l}\text { Heterosexual } \\
\text { couple }(\text { male }+ \text { ) }\end{array}$ & $\begin{array}{l}\text { Fertility } \\
\text { treatment } \\
\text { then } \\
\text { adoption }\end{array}$ & Successful & Included \\
\hline Interviewee 3 & Alan (White) & $\begin{array}{l}\text { Single } \\
\text { homosexual } \\
\text { man }\end{array}$ & $\begin{array}{l}\text { Adoption } \\
\text { only }\end{array}$ & Successful & Included \\
\hline Interviewee 4 & $\begin{array}{l}\text { Jenny (White) } \\
\text { Dean (White) }\end{array}$ & $\begin{array}{l}\text { Heterosexual } \\
\text { couple (male +) }\end{array}$ & $\begin{array}{l}\text { Adoption } \\
\text { only }\end{array}$ & Successful & Included \\
\hline Interviewee 5 & $\begin{array}{lrr}\text { Angie } & (42 & \text { yr } \\
\text { old } & \text { Black } \\
\text { African } & + \\
\text { White) } & \end{array}$ & $\begin{array}{l}\text { Heterosexual } \\
\text { female }\end{array}$ & $\begin{array}{l}\text { Fertility } \\
\text { treatment }\end{array}$ & Unsuccessful & Excluded \\
\hline Interviewee 6 & $\begin{array}{l}\text { Kelsea (Black } \\
\text { African) } \\
\text { Trev (Black } \\
\text { African) }\end{array}$ & $\begin{array}{l}\text { Heterosexual } \\
\text { couple (male }+ \text { ) }\end{array}$ & $\begin{array}{l}\text { Fertility } \\
\text { treatment }\end{array}$ & Successful & Excluded \\
\hline Interviewee 7 & $\begin{array}{l}\text { Malvern (Black } \\
\text { African) }\end{array}$ & $\begin{array}{l}\text { Heterosexual } \\
\text { Male (both }+ \text { ) }\end{array}$ & $\begin{array}{l}\text { Fertility } \\
\text { treatment }\end{array}$ & Unsuccessful & Excluded \\
\hline Interviewee 8 & $\begin{array}{l}\text { Rean (Black } \\
\text { African) }\end{array}$ & $\begin{array}{l}\text { Heterosexual } \\
\text { male (female }+ \text { ) }\end{array}$ & $\begin{array}{l}\text { Fertility } \\
\text { treatment }\end{array}$ & Unsuccessful & Excluded \\
\hline Interviewee 9 & $\begin{array}{l}\text { Leanne } \\
\text { (Asian) }\end{array}$ & $\begin{array}{l}\text { Heterosexual } \\
\text { female }(\text { male }+)\end{array}$ & $\begin{array}{l}\text { Fertility } \\
\text { treatment }\end{array}$ & Unsuccessful & Excluded \\
\hline $\begin{array}{l}\text { Interviewee } \\
10\end{array}$ & $\begin{array}{l}\text { Gabriella } \\
\text { (White) } \\
\text { Brad (White) }\end{array}$ & $\begin{array}{l}\text { Heterosexual } \\
\text { couple (both +) }\end{array}$ & $\begin{array}{l}\text { Adoption } \\
\text { only }\end{array}$ & $\begin{array}{l}\text { Successful, } \\
\text { international } \\
\text { adoption. }\end{array}$ & Included \\
\hline $\begin{array}{l}\text { Interviewee } \\
11\end{array}$ & $\begin{array}{l}\text { Trisha (Black } \\
\text { African) } \\
\text { 30yrs old }\end{array}$ & $\begin{array}{l}\text { Heterosexual } \\
\text { female (both }+ \text { ) }\end{array}$ & $\begin{array}{l}\text { Fertility } \\
\text { treatment }\end{array}$ & Successful & Excluded \\
\hline
\end{tabular}


Diagram 1: Visual framework for the intersectional stigmas associated with PLWHIV seeking adoption and how they interact with the process of assessing prospective adopters.

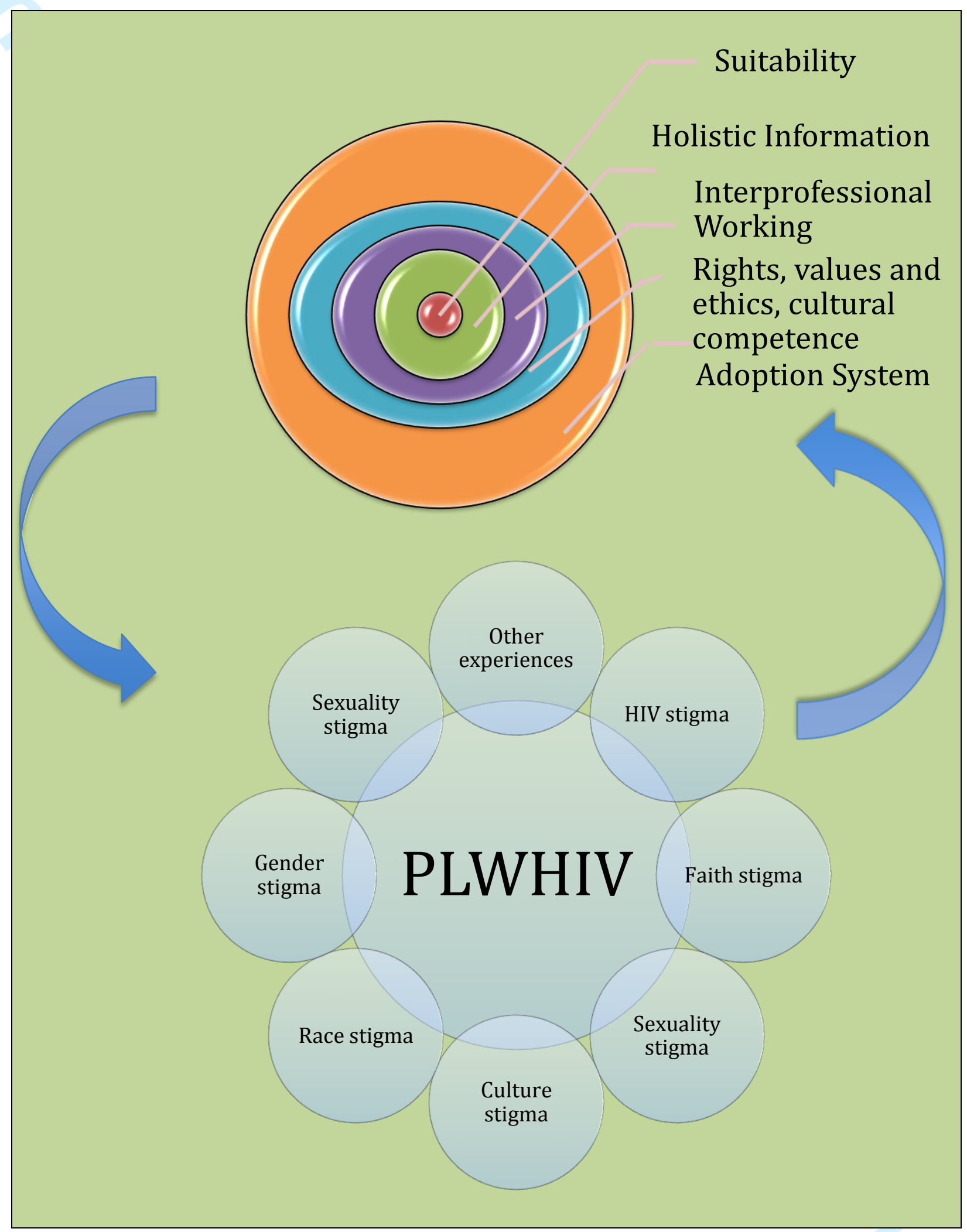

